\title{
Not the story you want? Assessing the fit of a conceptual framework characterising mental health recovery narratives
}

\author{
Joy Llewellyn-Beardsley ${ }^{1}\left[\right.$. Stefan Rennick-Egglestone ${ }^{1} \cdot$ Simon Bradstreet $^{2} \cdot$ Larry Davidson $^{3}$. \\ Donna Franklin ${ }^{4} \cdot$ Ada Hui $^{1} \cdot$ Rose McGranahan ${ }^{5} \cdot$ Kate Morgan $^{1} \cdot$ Kristian Pollock $^{6} \cdot$ Amy Ramsay $^{7} \cdot$ Roger Smith $^{4}$. \\ Graham Thornicroft ${ }^{6} \cdot$ Mike Slade $^{1}$
}

Received: 4 June 2019 / Accepted: 9 October 2019 / Published online: 25 October 2019

(c) The Author(s) 2019

\begin{abstract}
Purpose Narratives of recovery have been central to the development of the recovery approach in mental health. However, there has been a lack of clarity around definitions. A recent conceptual framework characterised recovery narratives based on a systematic review and narrative synthesis of existing literature, but was based on a limited sample. The aims of this study were to assess the relevance of the framework to the narratives of more diverse populations, and to develop a refined typology intended to inform narrative-based research, practice and intervention development.

Method 77 narrative interviews were conducted with respondents from four under-researched mental health sub-populations across England. Deductive and inductive analysis was used to assess the relevance of the dimensions and types of the preliminary typology to the interview narratives.

Results Five or more dimensions were identifiable within $97 \%$ of narratives. The preliminary typology was refined to include new definitions and types. The typology was found not to be relevant to two narratives, whose narrators expressed a preference for non-verbal communication. These are presented as case studies to define the limits of the typology.

Conclusion The refined typology, based on the largest study to date of recovery narratives, provides a defensible theoretical base for clinical and research use with a range of clinical populations. Implications for practice include ensuring a heterogeneous selection of narratives as resources to support recovery, and developing new approaches to supporting non-verbal narrative construction.
\end{abstract}

Keywords Mental health $\cdot$ Recovery $\cdot$ Narrative $\cdot$ Qualitative

Electronic supplementary material The online version of this article (https://doi.org/10.1007/s00127-019-01791-x) contains supplementary material, which is available to authorized users.

Joy Llewellyn-Beardsley

joy.llewellyn-beardsley@nottingham.ac.uk

1 School of Health Sciences, Institute of Mental Health, University of Nottingham, Nottingham, UK

2 Institute of Health and Wellbeing, University of Glasgow, Glasgow, UK

3 Yale School of Medicine, Yale University, New Haven, USA

4 NEON Lived Experience Advisory Panel, Nottingham, UK

\section{Introduction}

Mental health recovery narratives are first-person lived experience accounts of recovery from mental health problems, which include elements of adversity or struggle and of selfdefined strengths, successes or survival [1]. They have been described as a "key recovery technology" [2], central to the

5 Unit of Social and Community Psychiatry, Queen Mary University of London, London, UK

6 School of Health Sciences, University of Nottingham, Nottingham, UK

7 Health Service and Population Research Department, Centre for Implementation Science, Institute of Psychiatry, Psychology and Neuroscience, King's College London, London, UK 
recovery approach within mental health policy and practice $[3,4]$. Interventions have been developed to support individuals to write [5] and tell [6] their own stories, and guidelines on sharing recovery narratives have been produced [7-9]. The recovery narratives of others have been used as a resource by practitioners [10], online mental health interventions [11] and anti-stigma campaigns [12]. For recipients, recovery narratives can provide personal inspiration [6], authenticate difficult personal experiences [11] or mitigate social isolation [13]. They can also contribute to distress, e.g. a recipient may feel inadequate if they perceive the narrator has made a 'better' recovery [14].

Despite wide-ranging use in mental health practice, and the possibility of creating both benefits and harms, there has been a lack of conceptual clarity and consistency in the definition of recovery narratives [1]. A clearer understanding of their characteristics could ensure that future use of narratives in clinical interventions and practice provide maximum benefit and minimum harms to recipients. Providing conceptual clarity is one contribution that research can make to clinical practice. Recent examples include conceptual frameworks [15] for childhood maltreatment [16], social isolation [17] and pathways to mental health care [18].

The authors have previously developed a conceptual framework for mental health recovery narratives ${ }^{1}$ through a systematic review and narrative synthesis [1]. Included studies used various terms to describe such narratives, including 'illness and recovery narratives', 'user narratives', 'life histories', and 'emotional distress narratives', but these were not necessarily synonymous concepts. The review synthesised 45 empirical studies to produce a conceptual framework comprising nine overarching dimensions: Genre, Positioning (in relation to the mental health system), Emotional Tone, Relationship with Recovery, Trajectory, Use of Turning Points, Narrative Sequences, Protagonists and Use of Metaphor [1], called here the Recovery Narratives Conceptual Framework (RNCF). It also proposed the above definition of recovery narratives, based on those found in included studies [19, 20].

The RNCF was developed to provide a theoretical basis to inform research, practice and development of narrativebased interventions. However, the studies it was based on collectively exhibited biases. The recovery approach has been criticised for being based on mono-cultural, predominantly Western assumptions [21], so broader concepts from more collectivist and interdependent approaches need to be incorporated [22]. The systematic review supports this critique. Included studies came from a small range of mainly

\footnotetext{
1 The conceptual framework can be viewed here: https://journals. plos.org/plosone/article/figure $? \mathrm{id}=10.1371$ /journal.pone .02146 78.t001.
}

white-majority countries. 17\% of participants were from Black, Asian and Minority Ethnic (BAME) communities. The majority of studies used convenience samples of participants currently or previously using mental health services, hence excluding narratives from those who recover outside of services. Some of the included studies used purposive sampling of recovery narratives described by researchers as exemplary [20] or seminal accounts [23] that were "exceptional in their richness" [24]. These were commonly from narrators described as being in possession of significant "intellectual, cultural and symbolic capital" [25], which may have led to an under-representation of narratives from those experiencing recovery without access to similar socioeconomic, cultural or environmental resources.

As the RNCF is based on a relatively homogenous sample, there is a risk that it may not be relevant for more heterogeneous groups, in not being applicable to more diverse narratives and/or by omitting knowledge available from more diverse populations. In previous research, this risk has been addressed through studies that assess the relevance, or 'fit', of an existing framework with a more heterogeneous group. In one example, a systematic review of studies of recovery produced a conceptual framework comprising five recovery processes: Connectedness, Hope, Identity, Meaning and Empowerment (CHIME) [26]. The framework was based on published narratives of past recovery, so the relevance for current mental health service users was unknown. The fit of the framework was assessed through deductive and inductive thematic analysis of focus groups held with current mental health service users [27]. This confirmed that the CHIME processes were present in their accounts, hence validating the framework's relevance, and highlighted additional aspects of recovery for that population, hence refining the framework.

The aims of this study were (1) to assess the overall fit of the previously-developed RNCF with data collected from narrative interviews with groups not well-represented in the original systematic review, and (2) to develop a typology of recovery narratives incorporating identified refinements. The typology is intended to inform narrative-based practice, research and intervention development.

\section{Methods}

The research was undertaken as part of the Narrative Experiences Online (NEON) study (information at http://www. researchintorecovery.com/neon) between March and August 2018. Ethical Committee approval was obtained (Nottingham 2 REC 17/EM/0401). All participants provided written informed consent. Findings will inform a future trial (ISRCTN11152837). 


\section{Study design}

Recovery narratives were collected from under-researched populations. A preliminary typology was developed in order to operationalise the RNCF. Co-analysis was conducted with the NEON Lived Experience Advisory Panel (LEAP) to refine the preliminary typology. Analysis was conducted to assess the fit of the RNCF through (a) relevance to the chosen populations (whether the majority of dimensions were present in the majority of recovery narratives) and (b) comprehensiveness (whether existing types within each dimension sufficiently described the narrative characteristics of this population).

\section{Participants}

A purposive sample of four groups of participants were recruited, spanning a range of populations that were underrepresented in the review on which the conceptual framework was based. Inclusion criteria common to all groups were: aged over 18; willing to discuss experiences; able to give informed consent; fluent in English.

Additional inclusion criteria were as follows: Group A (Outside the system), people with self-identified experiences of psychosis and no use of secondary mental health services over the previous five years. Group B (BAME), people from Black, Asian and minority ethnic (BAME) communities currently using mental health services. Group C (Underserved), people not well-engaged with by mental health services, operationalised as: people from lesbian, gay, bisexual or trans (LGBT+) communities [28]; people with multiple and complex health/social care needs (mental health issues and at least two of homelessness, substance misuse issues or offending) [29]; and people from rural communities (less than 10,000 population) [30]. Group D (Peer), people with experience of working in statutory or voluntary roles for which lived experience is a requirement, e.g. peer support workers, trainers or researchers.

\section{Setting}

Participants were recruited across England; Groups A and B primarily from London, and Groups $C$ and D primarily from the Midlands. Group A (Outside the System) were recruited through primary care services, online support groups, Hearing Voices networks and online advertising. Group B (BAME) were recruited in London through community groups, a Recovery College and secondary mental health services. Group C (Under-served) were recruited through voluntary and community sector organisations and secondary care mental health services. Group D (Peer) were recruited through community groups and secondary care mental health services. Participants for all groups were recruited using snowball sampling.

\section{Procedures}

To enhance the role of lived experience in the collection and analysis of data, a co-analysis workshop [31] was held in October 2018 with eight members of the NEON LEAP who had experience of working with recovery narratives. Panel members were asked to apply two dimensions of the typology to their own recovery narratives, in order to refine how the typology was applied in practice. LEAP co-analysis demonstrated that more than one type could apply to a narrative, enabling a more nuanced approach to categorisation. For example within the Genre dimension, a narrative of the 'escape' type (narratives of escape from and resistance to abuse, threat, stigma and persecution) may also contain elements of the 'endurance' type (narratives of loss, trauma, difficult circumstances and/or seemingly insurmountable odds).

Semi-structured interviews were conducted by four researchers from narrative, advocacy, public health and health psychology backgrounds (JLB, KM, AR and RM). Each participant took part in a 40-90 min interview conducted in health services or community venues. The full topic guide is shown in Online Resource 1. In line with a narrative inquiry approach [4], the first part of the topic guide comprised an open-ended question designed to elicit a narrative [32], with minimal or no interruption from the researcher in order to facilitate fluent story-telling [33]. The participant was asked to share their mental ill health and recovery experiences as a story over time, with a beginning, middle, current situation and future considerations [9]. Interviews were recorded, transcribed and pseudonymised.

\section{Analysis}

A two-stage narrative inquiry approach was taken to analysing the narratives. This is an established qualitative method which has been identified as well-suited to mental health recovery research, particularly for under-researched populations [4]. Analysis was undertaken by a team of four experienced researchers (AH, AR, JLB, RM), co-ordinated by a qualitative lead (KP).

In stage one, narratives were analysed deductively to assess relevance, using a template based on the preliminary typology to identify whether the nine dimensions could be applied to the interview narratives. The template is presented as Online Resource 2. In stage two, inductive analysis was undertaken to assess comprehensiveness, through identifying areas of similarity with existing types and potential differences. Candidate refinements to the typology were 
Table 1 Clinical and sociodemographic characteristics of interview participants $(n=77)$

\begin{tabular}{|c|c|c|c|c|c|}
\hline Characteristic & Total & $\begin{array}{l}\text { Group A (outside } \\
\text { the system) }\end{array}$ & Group B (BAME) & $\begin{array}{l}\text { Group C } \\
\text { (under-served) }\end{array}$ & Group D (peer) \\
\hline$n(\%)$ & $77(100)$ & $21(27)$ & $21(27)$ & $19(25)$ & $16(21)$ \\
\hline \multicolumn{6}{|l|}{ Gender $n(\%)$} \\
\hline Female & $42(55)$ & $14(67)$ & $11(53)$ & $8(42)$ & $9(56)$ \\
\hline Male & $30(39)$ & $6(29)$ & $9(43)$ & $9(47)$ & $6(38)$ \\
\hline Other/prefer not to say & $5(6)$ & $1(5)$ & $1(5)$ & $2(11)$ & $1(6)$ \\
\hline \multicolumn{6}{|l|}{ Ethnicity $n(\%)$} \\
\hline White British & $44(57)$ & $12(57)$ & $0(0)$ & $18(95)$ & $14(88)$ \\
\hline Black British & $5(6)$ & $2(10)$ & $3(14)$ & $0(0)$ & $0(0)$ \\
\hline Black African/Caribbean & $4(5)$ & $1(5)$ & $3(14)$ & $0(0)$ & $0(0)$ \\
\hline White Other & $5(6)$ & $2(10)$ & $1(5)$ & $0(0)$ & $2(13)$ \\
\hline White and Black African/Caribbean & $4(5)$ & $0(0)$ & $4(19)$ & $0(0)$ & $0(0)$ \\
\hline Asian/Mixed white Asian & $4(5)$ & $0(0)$ & $4(19)$ & $0(0)$ & $0(0)$ \\
\hline Other & $5(6)$ & $2(10)$ & $3(14)$ & $0(0)$ & $0(0)$ \\
\hline Prefer not to say & $6(8)$ & $2(10)$ & $3(14)$ & $1(5)$ & $0(0)$ \\
\hline \multicolumn{6}{|l|}{ Age (years) } \\
\hline $18-25$ & $4(5)$ & $0(0)$ & $0(0)$ & $3(16)$ & $1(6)$ \\
\hline $25-34$ & $16(21)$ & $3(14)$ & $6(29)$ & $4(21)$ & $3(19)$ \\
\hline $35-44$ & $16(21)$ & $5(24)$ & $4(19)$ & $4(21)$ & $3(19)$ \\
\hline $45-54$ & $30(39)$ & $8(38)$ & $9(43)$ & $6(32)$ & $7(43)$ \\
\hline $55+$ & $5(6)$ & $4(19)$ & $0(0)$ & $0(0)$ & $1(6)$ \\
\hline Prefer not to say & $6(8)$ & $1(5)$ & $2(10)$ & $2(11)$ & $1(6)$ \\
\hline \multicolumn{6}{|l|}{ Sexual orientation } \\
\hline Heterosexual & $49(64)$ & $15(71)$ & $14(67)$ & $6(32)$ & $14(88)$ \\
\hline LGBT+ & $18(23)$ & $3(14)$ & $4(19)$ & $9(47)$ & $2(13)$ \\
\hline Prefer not to say & $10(13)$ & $3(14)$ & $3(14)$ & $4(21)$ & $0(0)$ \\
\hline \multicolumn{6}{|l|}{ Primary diagnosis } \\
\hline Schizophrenia or other psychosis & $11(14)$ & $5(24)$ & $4(19)$ & $2(11)$ & $0(0)$ \\
\hline Bipolar disorder/cyclothymia & $16(21)$ & $8(38)$ & $1(5)$ & $3(16)$ & $4(25)$ \\
\hline Mood disorder, e.g. anxiety, depression, dysthymia & $15(19)$ & $1(5)$ & $4(19)$ & $4(21)$ & $6(38)$ \\
\hline $\begin{array}{l}\text { Other, e.g. ADHD, personality disorder, substance } \\
\text { abuse, autism }\end{array}$ & 7 (9) & $0(0)$ & $2(10)$ & $3(16)$ & $2(13)$ \\
\hline Prefer not to say & $28(36)$ & $7(33)$ & $10(48)$ & $7(37)$ & $4(25)$ \\
\hline
\end{tabular}

discussed within a wider analysis team with expertise in mental health recovery research and health technology research. Decisions on refinements were made by consensus.

Narratives where five or more dimensions appeared not to be applicable were further discussed within the team. Narratives to which it was agreed less than five dimensions applied are presented as case studies demonstrating the limits of the typology.

\section{Results}

Seventy-seven interviews were conducted. Characteristics of participants are presented in Table 1 .

\section{Relevance and comprehensiveness}

The previously developed RNCF comprised nine overarching dimensions (Genre, Positioning, Emotional Tone, Relationship with Recovery, Trajectory, Use of Turning Points, Narrative Sequences, Protagonists and Use of Metaphor), each of which contained between two and six types. For the current study, this was operationalised as a preliminary typology.

Five or more of the nine dimensions within the typology were identified within 75 (97\%) of the 77 narratives. Example analysis of a narrative fitting existing dimensions and types is presented as Online Resource 2.

Not all dimensions were present in all narratives. Some did not contain the 'Turning Points' dimension, for example, 
attributing recovery to social factors rather than specific events:

I have got good people round me, so I guess that is the bulk of the story really, it is the people around me that have just been absolutely magnificent (B15).

The 'Relationship with Recovery' dimension was not present for one narrator, for good reason—she had rejected the concept, while attending a recovery college. This gave her a sense of freedom:

This is not really a good description of recovery $I$ guess, but for me kind of being able to reject recovery...sort of helped me in a way to - not feel better, but just to sort of feel 'me', and that I could make those decisions. I didn't have to get better if I didn't want to (D3).

As she was now a peer support worker, she felt "twofaced" in her rejection of recovery. She appeared apologetic that her story did not match what she thought was expected of her- "not the story you want, I'm sure".

The types within five dimensions (Genre, Relationship with Recovery, Use of Turning Points, Protagonists and Use of Metaphor) were assessed as comprehensively able to describe the narratives of these populations, e.g. further types did not emerge from the narratives. Additional types did emerge within four dimensions (Positioning, Emotional Tone, Trajectory and Narrative Sequences), and these are outlined below.

\section{Refinements}

Refinements were made to four dimensions, based on emergent themes from the LEAP co-analysis and interview data.

The 'Positioning' dimension originally referred to the way in which narrators position their recovery in relation to the mental health system, comprising three types: recovery 'within the system', 'despite the system' and 'outside of the system'. This reflected the language used in studies included in the original systematic review. LEAP co-analysis identified that this was not clear, as people experiencing mental health problems may be accessing multiple systems, e.g. housing. Types were renamed to refer to 'services' rather than 'the system'. The 'recovery within services' type was also extended to include two subtypes: (1) using services and (2) delivering services, reflecting that delivering or advising on services was central to some participants' recovery:

I was really taken aback when I learnt that actually having lived experience of mental health challenges was something that the NHS was interested in as an expertise. That was a real big turning point for me to realise that everything that I had gone through could actually benefit both myself and other people (D8).

The 'Emotional Tone' dimension describes the overall mood or feeling of the narrative. It originally contained six types ('buoyant', 'challenging', 'disenfranchised', 'reflective' and 'shaken'). A further six candidate additions to the framework emerged from the data ('matter of fact', 'frenetic', 'agitated', 'confused', 'apologetic' and 'humble'). To increase comprehensiveness, all types were then synthesised into four overarching types: 'upbeat', 'downbeat', 'critical' and 'neutral'.

The 'Trajectory' dimension describes the overall direction of a narrative towards its destination. It originally comprised four types ('upward spiral', 'up and down', 'horizontal' and 'interrupted'). However, a different type emerged from the narratives of participants identified as having multiple and complex needs-'cyclical' narratives, defined as 'cycling through sequences of distress, gradual recovery, a period of wellbeing and distress again'. Analysis indicated that these differed from the existing 'up and down' type, which also contained movement towards both recovery and distress. For example, narrators of circular narratives described a process of going back to the beginning during distress periods. There was no sense of the narrator presenting themselves within a "crisis to resolution" progression [34]:

I usually go through five year cycles where it starts off where I'll have everything, [then] throw it all away... burying my head in the sand, and then sort of like work through my own demons by blocking myself off, build myself back up again, get myself all the way back up there and then almost kick my own ladder from underneath me. (C9)

No benefits from previous periods of recovery/wellbeing were reported as being retained:

I just, mine goes in spells for quite a while, and they just come around, I get myself clean again, get back to work and then, I have done it for the last 20 years, exactly the same thing $(\mathrm{C} 8)$.

There was little or no sense that the cycle could be exited:

Because honestly I hate it you know every time I [use heroin]. It's like I'll do it. And I think well fucking hell I've done it again. You know I hate it, it's been like that for like ten years (C12).

Cyclical narratives fitted the recovery narrative definition included in the introduction, containing clear elements of strength, success or survival. The way in which success was represented appeared to be related to another dimension, the narrator's current 'Relationship with Recovery'. A narrative fitting the 'struggling day to day' 
type, i.e. relating to recovery as a process in which the narrator is tentatively engaging, described the cycle as:

A continuous battle and I think because of everything else that's going on it will be a continuous battle until the day I die (C9).

In contrast, a 'making progress' type narrative, where the narrator describes more confidence in their ability to tolerate distressing periods, reported a cycle in terms of pride in moving through these times:

I have been that low. And that ill, I have been there and I have seen the light ... and I have come back from it...I've been there, right there to the lowest of the low. And pulled myself back from it. And that's difficult to do (C12).

Two refinements were made to the 'Narrative Sequences' dimension, which describes the component parts of a recovery narrative. First, it originally comprised three types ('experiences of distress', 'turning point' and 'experiences of recovery'), each of which contained a number of sub-type sections (e.g. 'experiences of distress' contained five subtypes: 'life before illness/trauma', 'problems begin', 'problems worsen', 'impact of illness' and 'glimpses of recovery'). The dimension was renamed to 'Narrative Sections' for greater flexibility, as 'Narrative Sequences' suggested a linear progression through the types, whereas analysis showed that sections appeared in many different orders. Second, one 'Narrative Sections' type was renamed to better fit the data. The "Life before illness/trauma" section was identified in significantly fewer narratives than others $(n=15,19 \%)$; however, sections wherein narrators told of possible origins of their mental health distress were more prevalent. For example:

I didn't have a great home life. My dad was physically and emotionally quite abusive. My mum didn't leave him until I was about 18, so me and my brother were left in those circumstances.... When I have been unpicking it in the many years of therapy I have had since, that seems to be the root of a lot of it, not having a great home life, not having a great start (C14)

To better reflect this, the 'Life before illness/trauma' type was renamed to 'Origins', defined as a section containing 'possible roots or causes of later mental health distress, or descriptions of life before illness'.

The results of analysis of the 75 narratives for which the framework was assessed as relevant are presented as Table 2, incorporating all above changes.

\section{Outlier narratives}

In two of the 77 narratives, more than five dimensions could not be identified as relevant. Both were unconventionally structured, and both narrators described a preference for non-verbal forms of expression. Narrator B22 made several references to art being central to his recovery in terms of helping to construct a positive identity:

my ex-art teacher from [organisation] spoke very highly of me as well, okay, she said I was hard working and I could draw, I could do art work

and a sense of purpose:

I felt someone coming towards me but I couldn't see: “...God didn't mean to you to save the world okay, go back to England and become an artist”.

Narrator D15, a peer support worker, expressed his frustration with the focus within recovery services on telling stories, and his preference for non-verbal ways of communicating:

There has been so much focus as I said in the past in telling your story, telling your story, and the thing about dancing has been you don't have words...you are not supposed to talk during the dancing, um so you don't... get stuck in this cycle of this happened, this happened and then I did this and I feel so bad about this...I'm a terrible person.

Instead of using story, the narrator brought his experience of dance to the way he supported people:

The space where I am held when I go dancing, I try and bring that when I meet with someone. I try and allow the person to...express those things that they can't, don't feel they can in other open places.

The typology was assessed as not being relevant for these two narratives.

The final recovery narratives typology including all refinements to types and definitions is shown as Table 3.

\section{Discussion}

This study assessed the relevance and comprehensiveness of a conceptual framework through analysis of interviews with under-researched populations, in order to produce a typology of mental health recovery narratives. The study produced three main findings: (1) the RNCF was found to be relevant to the narratives of individuals from heterogeneous groups, (2) refinements were identified and incorporated into a more comprehensive recovery narratives typology, and (3) most experiences of recovery were expressible in words, but not 
Table 2 Categorisation of recovery narratives of under-researched groups (refinements underlined)

\begin{tabular}{|c|c|c|c|c|c|c|c|}
\hline \multirow[t]{2}{*}{ No. } & \multirow[t]{2}{*}{ Dimension } & \multirow{2}{*}{$\begin{array}{l}\text { Types } \\
n(\%)\end{array}$} & \multirow{2}{*}{$\begin{array}{l}\text { Total } \\
75(100)\end{array}$} & \multirow{2}{*}{$\begin{array}{l}\text { Group A (out- } \\
\text { side the system) } \\
21(28)\end{array}$} & \multirow{2}{*}{$\begin{array}{l}\text { Group B (BAME) } \\
20(27)\end{array}$} & \multirow{2}{*}{ 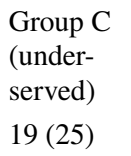 } & \multirow{2}{*}{$\begin{array}{l}\text { Group D (peer) } \\
15(20)\end{array}$} \\
\hline & & & & & & & \\
\hline \multirow[t]{4}{*}{1} & \multirow[t]{4}{*}{ Genre } & Escape & $6(8)$ & $2(10)$ & $2(10)$ & $0(0)$ & $2(13)$ \\
\hline & & Endurance & $21(28)$ & $4(19)$ & $6(30)$ & $7(37)$ & $4(27)$ \\
\hline & & Endeavour & $28(37)$ & $7(33)$ & $6(30)$ & $9(47)$ & $6(40)$ \\
\hline & & Enlightenment & $20(27)$ & $8(38)$ & $6(30)$ & $3(16)$ & $3(20)$ \\
\hline \multirow[t]{3}{*}{2} & \multirow[t]{3}{*}{ Positioning } & Within services & 37 (49) & $6(28.5)$ & $10(50)$ & $12(63)$ & $9(60)$ \\
\hline & & $\underline{\text { Despite services }}$ & $18(24)$ & $9(43)$ & $5(25)$ & $1(0.5)$ & $3(20)$ \\
\hline & & Outside of services & $20(27)$ & $6(28.5)$ & $5(25)$ & $6(31.5)$ & $3(20)$ \\
\hline \multirow[t]{4}{*}{3} & \multirow[t]{4}{*}{ Emotional Tone } & Upbeat & $49(65)$ & $15(72)$ & $14(70)$ & $8(42)$ & $12(79)$ \\
\hline & & Downbeat & $8(11)$ & $0(0)$ & $3(15)$ & $4(21)$ & $1(7)$ \\
\hline & & Challenging & $15(20)$ & $3(14)$ & $3(15)$ & $4(21)$ & $1(7)$ \\
\hline & & $\underline{\text { Neutral }}$ & $7(9)$ & $3(14)$ & $0(0)$ & $3(16)$ & $1(7)$ \\
\hline \multirow[t]{5}{*}{4} & \multirow[t]{5}{*}{ Relationship with Recovery } & Recovered & $4(5)$ & $3(14)$ & $0(0)$ & $0(0)$ & $1(7)$ \\
\hline & & Living well & $36(48)$ & $13(62)$ & $10(50)$ & $5(26)$ & $8(52)$ \\
\hline & & Making progress & $21(28)$ & $5(24)$ & $4(20)$ & $8(42)$ & $4(27)$ \\
\hline & & Surviving day to day & 13 (17) & $0(0)$ & $6(30)$ & $6(32)$ & $1(7)$ \\
\hline & & Not applicable & $1(2)$ & $0(0)$ & $0(0)$ & $0(0)$ & $1(7)$ \\
\hline \multirow[t]{5}{*}{5} & \multirow[t]{5}{*}{ Trajectory } & Upward & $46(61)$ & $14(67)$ & $14(70)$ & $7(37)$ & $11(73)$ \\
\hline & & Up and down & $15(20)$ & $4(19)$ & $3(15)$ & $5(26)$ & $3(20)$ \\
\hline & & Horizontal & $8(11)$ & $3(14)$ & $2(10)$ & $2(11)$ & $1(7)$ \\
\hline & & Interrupted & $1(1)$ & $0(0)$ & $1(5)$ & $0(0)$ & $0(0)$ \\
\hline & & Cyclical & $5(7)$ & $0(0)$ & $0(0)$ & $5(26)$ & $0(0)$ \\
\hline \multirow[t]{4}{*}{6} & \multirow[t]{4}{*}{ Use of Turning Points } & Restorying & $14(18)$ & $6(29)$ & $2(10)$ & $2(10)$ & $4(31)$ \\
\hline & & Change for the better & $29(39)$ & $11(52)$ & $5(25)$ & $7(37)$ & $6(38)$ \\
\hline & & Better and worse & $29(39)$ & $3(14)$ & $12(60)$ & $10(53)$ & $4(25)$ \\
\hline & & Not applicable & $3(4)$ & $1(5)$ & $1(5)$ & $0(0)$ & $1(6)$ \\
\hline \multirow[t]{8}{*}{7} & \multirow[t]{8}{*}{ Narrative Sections } & $\underline{\text { Origins }}$ & $26(35)$ & $8(38)$ & $8(40)$ & $6(31)$ & $4(27)$ \\
\hline & & Problems begin & $70(93)$ & $20(95)$ & $18(90)$ & $18(95)$ & $14(93)$ \\
\hline & & Problems worsen & $70(93)$ & $20(95)$ & $18(90)$ & $19(100)$ & $13(87)$ \\
\hline & & Impact of illness & $56(75)$ & $16(76)$ & $12(60)$ & $15(79)$ & $13(87)$ \\
\hline & & Glimpses of recovery & $59(78)$ & $19(90)$ & $15(75)$ & $13(68)$ & $12(80)$ \\
\hline & & Turning point & $65(87)$ & $18(86)$ & $17(85)$ & $16(84)$ & $14(93)$ \\
\hline & & Roads to recovery & $71(95)$ & $21(100)$ & $19(95)$ & $17(89)$ & $14(93)$ \\
\hline & & Life afterwards & $64(85)$ & $19(90)$ & $17(85)$ & $16(84)$ & $12(80)$ \\
\hline \multirow[t]{3}{*}{8} & \multirow[t]{3}{*}{ Protagonists } & Personal factors & $72(94)$ & $20(95)$ & $20(95)$ & $17(89)$ & $15(100)$ \\
\hline & & Socio-cultural factors & $73(96)$ & $21(100)$ & $20(95)$ & $17(89)$ & $15(100)$ \\
\hline & & Systemic factors & $52(68)$ & $12(60)$ & $16(76)$ & $15(79)$ & $9(60)$ \\
\hline \multirow[t]{2}{*}{9} & Use of metaphor & Distress metaphors & $43(57)$ & $15(71)$ & $11(55)$ & $7(37)$ & $10(67)$ \\
\hline & & Recovery metaphors & $35(47)$ & $13(62)$ & $9(45)$ & $6(31)$ & $7(47)$ \\
\hline
\end{tabular}

all. All three findings have implications for mental health practice.

First, the typology was found to be relevant to narratives of individuals experiencing diverse forms of recovery involving many different factors. This finding supports research which presents recovery as a multidimensional process, involving biomedical, psychological, social and socio-political components [35]. It strengthens the original systematic review evidence that there are multiple dimensions and types of recovery narrative [1]. This is an important consideration for practitioners such as peer support workers or clinicians offering their own or others' stories to support recovery; and those supporting narrative production, such as facilitators of narrative-based courses within 


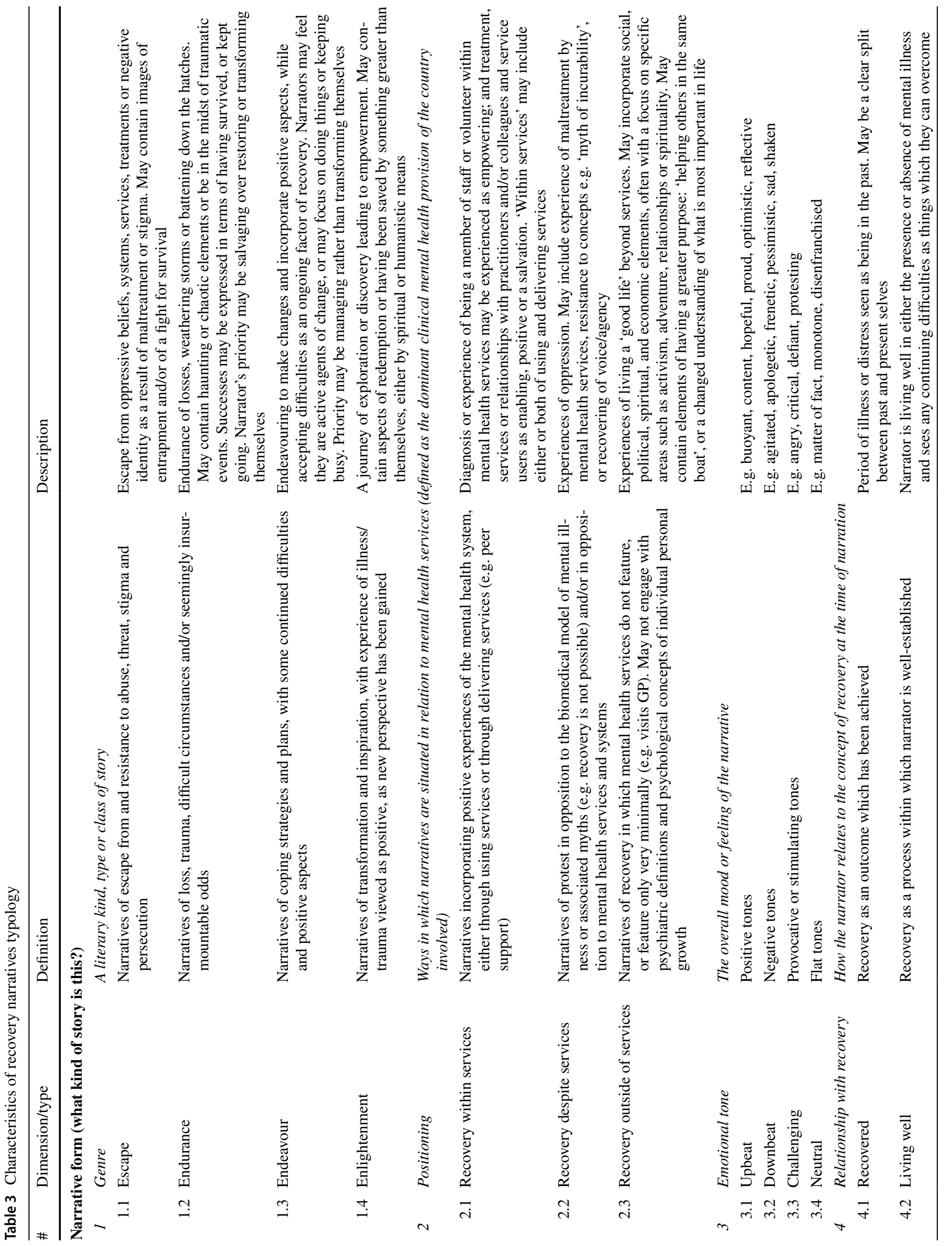




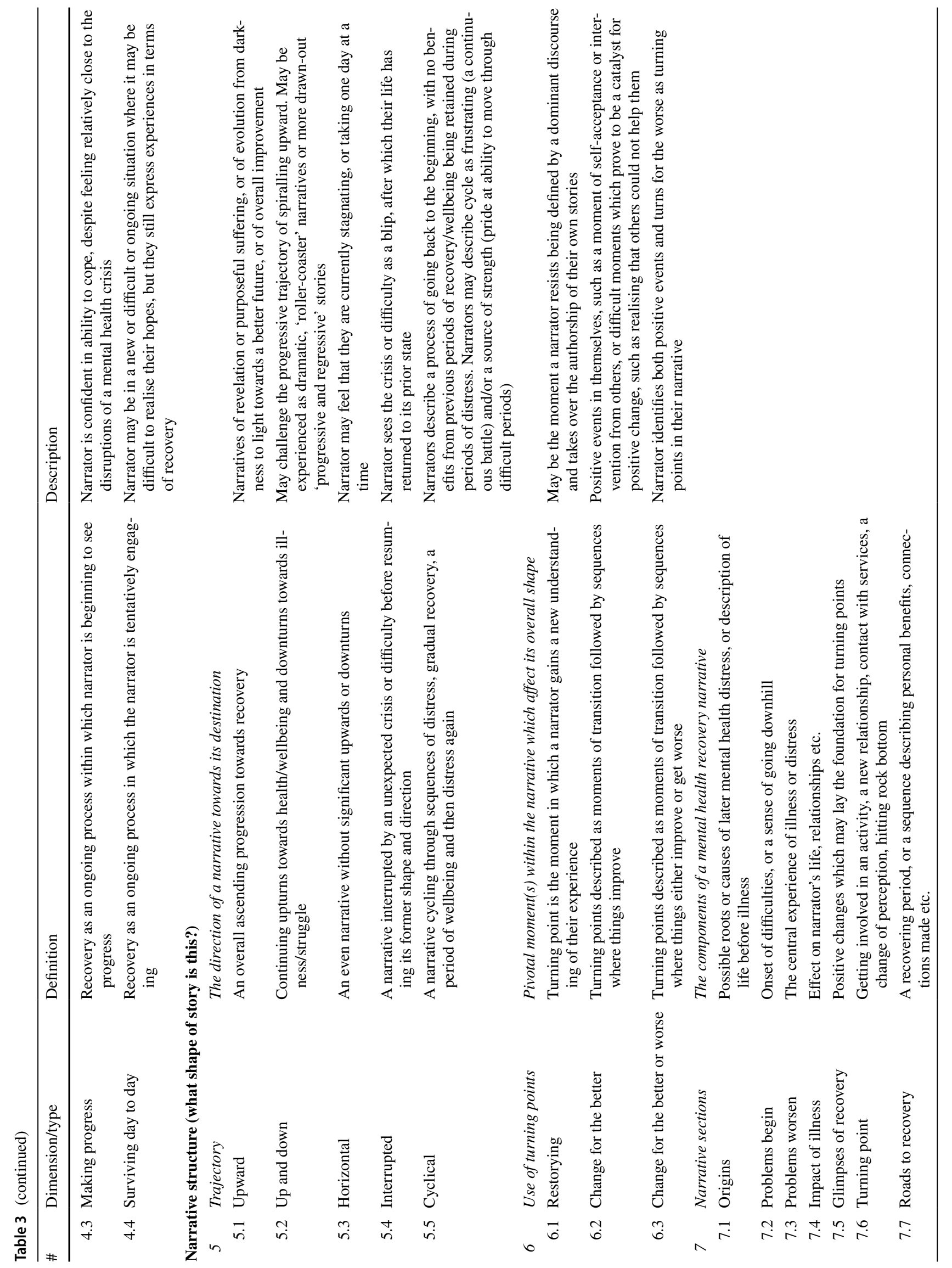


Recovery Colleges or those designing advocacy campaigns. For example, the manualised REFOCUS intervention [36, 37] uses narrative approaches to help articulate a service user's values, including suggested prompts [38]. This could be expanded to include prompts based on the typology, demonstrating to service users that multiple types of recovery story are equally possible and valid.

Courses [6] and guidance [7, 8] on developing one's recovery story are widely offered by recovery-based services. However, concerns have been raised that these could lead to the emergence of "dominant recovery narratives" at the expense of other types of experience [6]. Narrow interpretations of recovery narratives may be operationalised for organisational rather than individual benefit [39], whether by mental health services, charities and campaigns, which may promote narratives of returns to productivity via treatment and medication, or by activist movements, which may promote narratives of rejecting medication and finding the tools to cope with trauma without drugs [41]. These forms of "Recovery Narrative", dependent upon "tight adherence to generic conventions" for their efficacy [40], may put pressure on narrators to conform to particular types of narrative depending on their context [41]. This effect can be seen in the statement from an apologetic narrator above, a peer support worker in a recovery college, who felt her story was "not the story you want, I'm sure".

Contrary to this fear, the typology presented here speaks to this pressure by providing an evidence base which reinforces the multiplicity of forms, structures and content possible for recovery narratives. 'Endurance' and 'struggling day to day' narratives challenge the "compulsory positivity" [42] of some organisational agendas, while offering hope to recipients in the form of reducing isolation. Socio-cultural and systemic factors within the typology challenge narrativebased interventions which may promote storylines which "deflect attention from systemic inequalities and social injustice" [40]. The presence of 'downbeat' and 'neutral' tones support the inclusion of stories which may not conform to a "genre of inspiration", required to be emotionally uplifting [40], but which may be experienced as more authentic, a key moderator for positive impact on a recipient [14]. As evidence of both benefits and harms of stories emerges [43] it becomes increasingly important that individuals are offered a variety of examples, to maximise their chances of experiencing connection and hope [44].

For curators and editors of recovery narrative collections, the typology enables the development of a narrative measure to assess diversity within a collection, both by allowing heterogeneity to be measured and identifying missing types of narrative. This measure will be developed as part of the NEON Study, and may be an important tool for curators of recovery narrative collections who wish to minimise harm. For example, another moderator for positive impact is the 
recipient's own current relationship with recovery [14]. Curators of UK collection Beyond the Storms [45] found that its publication, though well-received, created a demand for other kinds of stories. The editor of the recent companion collection, Riding the Storms, reported that "the good intention of trying to give hope [in Beyond the Storms] was backfiring...for some people, they were perversely making things worse and not offering hope. That's not to say that the stories in Riding the Storms don't offer hope but...it's more about offering hope by helping people feel less alone" (personal communication, 24.01.2019). By considering the multiple dimensions and types of recovery narrative identified here, curators could build collections more likely to have a positive impact on the widest possible range of recipients.

The second finding was that the comprehensiveness of the typology was refined in the light of data from underresearched groups. For example, stories can also be cyclical, and practitioners may have an important role as "holders of hope" [46] during periods of struggle when individuals may temporarily be unable to construct, hold onto or believe in their own previous narratives or periods of recovery. This may be particularly important when supporting those facing multiple challenges, who may be more likely to experience repeated periods of distress and attendant despondency.

Many narrators will not have experienced a chapter of 'life before' their mental health issues existed. Recent research has highlighted the overlap between childhood trauma and mental health problems [47-49]. Related frameworks, providing alternatives to diagnosis, give a central place to the construction of narratives in an individual's recovery [50]. The refinement of this narrative section to 'origins' results in a more trauma-informed typology [51, 52], while not excluding narrators whose origins may have been trauma-free.

Third, most recovery narratives were expressible in words, but not all. The typology was not relevant for two narratives. In their less conventional structures, both reached the limits of "tellability" [53, 54], making them initially 'difficult' for analysts to understand. Such narrators may be dismissed as incoherent [55], producing meaningless 'word salad' [56], thus incapable of 'insight' [57]. Instead they may prefer other forms of communication, or require a broader understanding of "narrative insight" [58] from the recipient. This finding could suggest that such concepts of "tellability" potentially reproduce what have been called sanist assumptions within mental health $[59,60]$. Such sanism can lead to "testimonial injustice" [61], wherein a narrator's credibility and capacity as a knowledge holder may be undermined by an identity prejudice held by the recipient. The primarily spoken and written narratives within mental health practice may thus need to be extended, and future research may develop typologies for non-verbal recovery narratives. Approaches providing alternative narrative modalities include Photovoice [62], participatory arts [63], dance [64], sports [65] and games-based interventions [66] in addition to the more established arts therapies already recommended by national guidelines for treatment of psychosis [67].

\section{Strengths and limitations of the study}

Study strengths include its large dataset, incorporating diverse populations who are currently seldom heard within mental health research. Despite describing significant mental health difficulties, over a third of participants responded 'prefer not to say' when asked about their primary diagnosis. Although reasons were not explored, this may indicate that participants disagreed with their diagnosis or with diagnostic frameworks, did not know their diagnosis, or had not sought one; demonstrating that participants came from under-researched groups as intended. Another strength is the identification of two outlier cases of recovery narratives for which the typology was not relevant.

A limitation is that no differentiation was made between family/friends and mental health staff within analysis of protagonists at the socio-cultural level. Future work may focus on investigating any differences in the representation of formal and informal carers within participants' recovery narratives. A recruitment limitation was the small number of young adults within the sample, with four people aged between 18 and 25 being recruited. Future work may focus on investigating differences in the recovery narratives of young adults. Another limitation relates to a criticism of narrative inquiry, which can be seen merely as a way of organising 'unruly data' [68] without providing further insight or empathy with the narrator [69]. However, this study supports the use of such analysis as a means of providing insights through considering narratives collectively. The emergence and recognition of particular types, across numerous and heterogeneous narratives, can provide the kind of evidence of similarity of experience (for example, the possibility of recovery outside of services) that single stories cannot claim. It may address the call to develop a tradition of rigorous research for the analysis and archiving of stories to create sustained change within policy and practice [70].

\section{Conclusions}

This study assessed the fit of a conceptual framework developed from a systematic review of the literature when applied to the narratives of respondents from under-researched groups. It demonstrated the relevance of the over-arching dimensions of the framework, and led to a refined, more comprehensive typology which may be used as an evidence base for narrative interventions. Implications for practice include the importance of a heterogeneous selection of 
narratives to support recovery, and supporting the use of non-verbal approaches to narrative construction.

Acknowledgements This article is independent research funded by the National Institute for Health Research (NIHR) under its Programme Grants for Applied Research Programme [Personal experience as a recovery resource in psychosis: Narrative Experiences Online (NEON) Programme, RP-PG-0615-20016]. Mike Slade acknowledges the support of Center for Mental Health and Substance Abuse, University of South-Eastern Norway and the NIHR Nottingham Biomedical Research Centre. Graham Thornicroft is supported by the NIHR Collaboration for Leadership in Applied Health Research and Care South London at King's College London NHS Foundation Trust. Graham Thornicroft also receives support from the National Institute of Mental Health of the National Institutes of Health under award number R01MH100470 (Cobalt study). GT is also supported by the UK Medical Research Council in relation to the Emilia (MR/S001255/1) and Indigo Partnership (MR/R023697/1) awards. The views expressed are those of the authors and not necessarily those of the NIHR or the Department of Health and Social Care. The authors would like to thank all organisations who assisted with participant recruitment, including: the Health Shop (Nottinghamshire Healthcare NHS Foundation Trust), the Homeless Health Team (Nottingham CityCare Partnership), and POW Nottingham.

\section{Compliance with ethical standards}

Conflicts of interest The authors declare that they have no conflicts of interest.

Ethical standards All persons gave their informed consent prior to their inclusion in the study. The study has obtained Ethical Committee approval (Nottingham 2 REC 17/EM/0401) and, therefore, has been performed in accordance with the ethical standards laid down in the 1964 Declaration of Helsinki and its later amendments.

Open Access This article is distributed under the terms of the Creative Commons Attribution 4.0 International License (http://creativeco mmons.org/licenses/by/4.0/), which permits unrestricted use, distribution, and reproduction in any medium, provided you give appropriate credit to the original author(s) and the source, provide a link to the Creative Commons license, and indicate if changes were made.

\section{References}

1. Llewellyn-Beardsley J, Rennick-Egglestone S, Callard F, Crawford P, Farkas M, Hui A, Manley D, McGranahan R, Pollock K, Ramsay A, Tore Sælør K, Wright N, Slade M (2019) Characteristics of mental health recovery narratives: systematic review and narrative synthesis. PLoS One 14(3):e0214678. https://doi. org/10.1371/journal.pone.0214678

2. Smith-Merry J, Freeman R, Sturdy S (2011) Implementing recovery: an analysis of the key technologies in Scotland. Int J Mental Health Syst 5(1): 11

3. Onken SJ, Craig CM, Ridgway P, Ralph RO, Cook JA (2007) An analysis of the definitions and elements of recovery: a review of the literature. Psychiatr Rehabil J 31(1):9

4. Spector-Mersel G, Knaifel E (2018) Narrative research on mental health recovery: two sister paradigms. J Mental Health 27(4):298-306
5. Scottish Recovery Network (2019) Write to recovery. https://www. writetorecovery.net/. Accessed 13 Feb 2019

6. Nurser K, Rushworth I, Shakespeare T, Williams D (2018) Personal storytelling in mental health recovery. Mental Health Rev J 23(1):25-36

7. Scottish Recovery Network (2009) Story sharing guidance. https :/www.scottishrecovery.net/wp-content/uploads/2016/08/SRN_ Story_sharing_guidance_new_logo.pdf. Accessed 30 Jan 2019

8. Substance Abuse Mental Health Services Administration (2018) Share Your story: a how-to guide for digital storytelling. https:// www.samhsa.gov/sites/default/files/programs_campaigns/brss_ tacs/samhsa-storytelling-guide.pdf. Accessed 25 Oct 2018

9. McAdams DP (1993) The stories we live by: personal myths and the making of the self. Guilford Press, New York

10. Sommer R (2003) The use of autobiography in psychotherapy. J Clin Psychol 59(2):197-205

11. Williams A, Fossey E, Farhall J, Foley F, Thomas N (2018) Recovery after psychosis: qualitative study of service user experiences of lived experience videos on a recovery-oriented website. J Med Internet Res Mental Health 5(2):e37

12. Pinfold V, Thornicroft G, Huxley P, Farmer P (2005) Active ingredients in anti-stigma programmes in mental health. Int Rev Psychiatry 17(2):123-131

13. Shaw L-K, Homewood J (2015) The effect of eating disorder memoirs in individuals with self-identified eating pathologies. J Nerv Ment Dis 203(8):591-595. https://doi.org/10.1097/ NMD.0000000000000347

14. Rennick-Egglestone S, Ramsay A, McGranahan R, LlewellynBeardsley J, Hui A, Pollock K, Repper J, Yeo C, Ng F, Roe J, Gillard S, Thornicroft G, Booth S, Slade M (2019) The impact of mental health recovery narratives on recipients experiencing mental health problems: qualitative analysis and change model. PLoS One (in review)

15. Jabareen Y (2009) Building a conceptual framework: philosophy, definitions, and procedure. Int J Qual Methods 8(4):49-62

16. Curran E, Adamson G, Rosato M, De Cock P, Leavey G (2018) Profiles of childhood trauma and psychopathology: US National Epidemiologic Survey. Soc Psychiatry Psychiatr Epidemiol 53(11):1207-1219

17. Wang J, Lloyd-Evans B, Giacco D, Forsyth R, Nebo C, Mann F, Johnson S (2017) Social isolation in mental health: a conceptual and methodological review. Soc Psychiatry Psychiatr Epidemiol 52(12):1451-1461

18. MacDonald K, Fainman-Adelman N, Anderson KK, Iyer SN (2018) Pathways to mental health services for young people: a systematic review. Soc Psychiatry Psychiatr Epidemiol 53(10):1005-1038

19. Hall JM (2011) Narrative methods in a study of trauma recovery. Qual Health Res 21(1):3-13

20. Thornhill H, Clare L, May R (2004) Escape, enlightenment and endurance: narratives of recovery from psychosis. Anthropol Med 11(2):181-199

21. Price-Robertson R, Obradovic A, Morgan B (2017) Relational recovery: beyond individualism in the recovery approach. Adv Mental Health 15(2):108-120

22. Tse S, Ng RM (2014) Applying a mental health recovery approach for people from diverse backgrounds: the case of collectivism and individualism paradigms. J Psychosoc Rehabil Mental Health 1(1):7-13

23. Ridgway $P$ (2001) Restorying psychiatric disability: learning from first person recovery narratives. Psychiatr Rehabil J 24(4):335

24. Matusek JA, Knudson RM (2009) Rethinking recovery from eating disorders: spiritual and political dimensions. Qual Health Res 19(5):697-707 
25. Grant A, Leigh-Phippard H, Short N (2015) Re-storying narrative identity: a dialogical study of mental health recovery and survival. J Psychiatr Ment Health Nurs 22(4):278-286

26. Leamy M, Bird V, Le Boutillier C, Williams J, Slade M (2011) Conceptual framework for personal recovery in mental health: systematic review and narrative synthesis. $\mathrm{Br} \mathrm{J}$ Psychiatry 199(6):445-452

27. Bird V, Leamy M, Tew J, Le Boutillier C, Williams J, Slade M (2014) Fit for purpose? Validation of a conceptual framework for personal recovery with current mental health consumers. Aust N Z J Psychiatry 48(7):644-653

28. Hudson-Sharp N, Metcalf H (2016) Inequality among lesbian, gay bisexual and transgender groups in the UK: a review of evidence. National Institute for Economic and Social Research. https://www. gov.uk/government/publications/inequality-among-lgbt-group s-in-the-uk-a-review-of-evidence. Accessed 26 Sept 2018

29. Kuluski K, Ho J, Hans K, Nelson M (2017) Community care for people with complex care needs: bridging the gap between health and social care. Int J Integr Care 17:1-11

30. Gunnell D, Wheeler B, Chang S, Thomas B, Sterne J, Dorling D (2012) Changes in the geography of suicide in young men: England and Wales 1981-2005. J Epidemiol Community Health 66:536-543

31. Jennings H, Slade M, Bates P, Munday E, Toney R (2018) Best practice framework for Patient and Public Involvement (PPI) in collaborative data analysis of qualitative mental health research: methodology development and refinement. BMC Psychiatry 18(1):213

32. Riessman CK (2008) Narrative methods for the human sciences. Sage, London

33. Spector-Mersel G, Knaifel E (2018) Narrative research on mental health recovery: two sister paradigms. J Mental Health 27:298-306

34. Toolan M (2012) Narrative: a critical linguistic introduction. Routledge, London

35. Williams CC, Almeida M, Knyahnytska Y (2015) Towards a biopsychosociopolitical frame for recovery in the context of mental illness. Br J Social Work 45(suppl_1):i9-i26

36. Slade M, Bird V, Clarke E, Le Boutillier C, McCrone P, Macpherson R, Pesola F, Wallace G, Williams J, Leamy M (2015) Supporting recovery in patients with psychosis through care by community-based adult mental health teams (REFOCUS): a multisite, cluster, randomised, controlled trial. Lancet Psychiatry 2(6):503-514

37. Bird V, Leamy M, Le Boutillier C, Williams J, Slade M (2014) REFOCUS: promoting recovery in mental health services, 2nd edn. Rethink Mental Illness, London

38. Wallace G, Bird V, Leamy M, Bacon F, Le Boutillier C, Janosik M, MacPherson R, Williams J, Slade M (2016) Service user experiences of REFOCUS: a process evaluation of a pro-recovery complex intervention. Soc Psychiatry Psychiatr Epidemiol 51(9):1275-1284

39. Slade M, Amering M, Farkas M, Hamilton B, O'Hagan M, Panther G, Perkins R, Shepherd G, Tse S, Whitley R (2014) Uses and abuses of recovery: implementing recovery-oriented practices in mental health systems. World Psychiatry 13(1):12-20

40. Woods A, Hart A, Spandler H (2019) The recovery narrative: politics and possibilities of a genre. Cult Med Psychiatry. https:// doi.org/10.1007/s11013-019-09623-y

41. De Wolfe K, Academic TB (2019) Our resistance to recovery stories. https://thepolyphony.org/2019/05/13/our-resistance-to-recov ery-narratives/. Accessed 24 May 2019

42. Carton T (2017) A welcome antidote to the evangelism of compulsory optimism and resilience. Adv Appl Sociol 7(02):83

43. Rennick-Egglestone S, Morgan K, Llewellyn-Beardsley J, Ramsay A, McGranahan R, Gillard S, Hui A, Ng F, Schneider J, Booth S,
Pinfold V, Davidson L, Franklin D, Bradstreet S, Arbour S, Slade M (2019) Mental health recovery narratives and their impact on recipients: systematic review and narrative synthesis. Can J Psychiatry. https://doi.org/10.1177/0706743719846108

44. Williams J, Leamy M, Bird V, Le Boutillier C, Norton S, Pesola F, Slade M (2015) Development and evaluation of the INSPIRE measure of staff support for personal recovery. Soc Psychiatry Psychiatr Epidemiol 50(5):777-786

45. Davidson L, Lynn L (2013) Beyond the storms: reflections on personal recovery in Devon. Devon Partnership NHS Trust, Devon

46. Schrank B, Bird V, Rudnick A, Slade M (2012) Determinants, self-management strategies and interventions for hope in people with mental disorders: systematic search and narrative review. Soc Sci Med 74(4):554-564

47. Bentall RP, de Sousa P, Varese F, Wickham S, Sitko K, Haarmans M, Read J (2014) From adversity to psychosis: pathways and mechanisms from specific adversities to specific symptoms. Soc Psychiatry Psychiatr Epidemiol 49(7):1011-1022

48. Cooke A, Basset T, Bentall R, Boyle M, Cupitt C, Dillon J (2014) Understanding psychosis and schizophrenia. British Psychological Society, London

49. Longden E, Sampson M, Read J (2016) Childhood adversity and psychosis: generalised or specific effects? Epidemiol Psychiatric Sci 25(4):349-359

50. Johnstone L, Boyle M, Cromby J, Dillon J, Harper D, Kinderman P, Longden E, Pilgrim D, Read J (2018) The power threat meaning framework: towards the identification of patterns in emotional distress, unusual experiences and troubled or troubling behaviour, as an alternative to functional psychiatric diagnosis. British Psychological Society, Leicester

51. Cooke A (2017) Understanding psychosis and schizophrenia: why people sometimes hear voices, believe things that others find strange, or appear out of touch with reality... and what can help. British Psychological Society, Leicester

52. Sweeney A, Clement S, Filson B, Kennedy A (2016) Traumainformed mental healthcare in the UK: what is it and how can we further its development? Mental Health Rev J 21(3):174-192

53. Norrick NR (2005) The dark side of tellability. Narrat Inquiry 15(2):323-343

54. Ochs E, Capps L (2009) Living narrative: creating lives in everyday storytelling. Harvard University Press, Boston

55. Baldwin C (2005) Narrative, ethics and people with severe mental illness. Aust N Z J Psychiatry 39(11-12):1022-1029

56. Mitchell M, Hollingshead K, Coppersmith G (2015) Quantifying the language of schizophrenia in social media. In: Proceedings of the 2nd workshop on computational linguistics and clinical psychology: from linguistic signal to clinical reality, pp 11-20

57. Lysaker PH, Clements CA, Plascak-Hallberg CD, Knipscheer SJ, Wright DE (2002) Insight and personal narratives of illness in schizophrenia. Psychiatry Interpers Biol Process 65(3):197-206

58. Roe D, Hasson-Ohayon I, Kravetz S, Yanos PT, Lysaker PH (2008) Call it a monster for lack of anything else: narrative insight in psychosis. J Nerv Ment Dis 196(12):859

59. Perlin ML (2002) You have discussed lepers and crooks: sanism in clinical teaching. Clin Law Rev 9:683

60. Poole J, Jivraj T, Arslanian A, Bellows K, Chiasson S, Hakimy H, Pasini J, Reid J (2012) Sanism, 'mental health', and social work/ education: a review and call to action. Intersect Glob J Social Work Anal Res Polity Pract 1(1):20-36

61. Fricker M (2007) Epistemic injustice: power and the ethics of knowing. Oxford University Press, Oxford

62. Sutton-Brown CA (2014) Photovoice: a methodological guide. Photogr Cult 7(2):169-185

63. Stickley T, Wright N, Slade M (2018) The art of recovery: outcomes from participatory arts activities for people using mental health services. J Ment Health 27(4):367-373 
64. Ravelin T, Kylmä J, Korhonen T (2006) Dance in mental health nursing: a hybrid concept analysis. Issues Mental Health Nursing 27(3):307-317

65. Carless D, Douglas K (2008) Narrative, identity and mental health: how men with serious mental illness re-story their lives through sport and exercise. Psychol Sport Exerc 9(5):576-594

66. Kerr DJ, Deane FP, Crowe TP (2019) Narrative identity reconstruction as adaptive growth during mental health recovery: a narrative coaching boardgame approach. Front Psychol. https://doi. org/10.3389/fpsyg.2019.00994
67. National Collaborating Centre for Mental Health (2014) Psychosis and schizophrenia in adults: treatment and managementvol (NICE Clinical Guidelines, No. 178) 2, psychosis and schizophrenia in adults. National Institute for Health and Care Excellence, London

68. Bleakley A (2005) Stories as data, data as stories: making sense of narrative inquiry in clinical education. Med Educ 39(5):534-540

69. Bal M (2009) Narratology: Introduction to the theory of narrative. University of Toronto Press, Toronto

70. Rhodes P, De Jager A (2014) Narrative studies of recovery: a critical resource for clinicians. Clin Psychol 18(3):99-107 